\title{
Retinoblastoma cT4a TNM Finding v7
}

National Cancer Institute

\section{Source}

National Cancer Institute. Retinoblastoma cT4a TNM Finding v7. NCI Thesaurus. Code C88765.

Invasion of the optic nerve. (from AJCC 7th Ed.) 